\title{
OBSERVAÇÕES CLÍNICAS E LABORATORIAIS EM CÃES COM CINOMOSE NERVOSA
}

\author{
CLINICAL AND LABORATORY FINDINGS IN DOGS WITH DISTEMPER \\ ENCEPHALOMYELITIS
}

\author{
Eduardo Alberto Tudury ${ }^{1}$ Mônica Vicky Bahr Arias ${ }^{2} \quad$ Ana Paula Frederico Loureiro Bracarense $^{3}$ \\ Jane Megid $^{4}$ Rubens Ferreira Dias Júnior ${ }^{5}$
}

\section{RESUMO}

Em 81 cães com sinais clínicos, lesões histológicas e corpúsculos de inclusão no sistema nervoso central característicos de cinomose nervosa foi constatada ocorrência freqüente de: alteração das reações posturais (87,65\%), diminuição da secreção lacrimal $(83,95 \%)$, presença de mioclonias $(75,30 \%)$, paresias $(69,12 \%)$, conjuntivite $(56,79 \%)$, corioretinitel hiperqueratose naso-digital (51,85\%), linfopenia (51,85\%), anemia $(48,05 \%)$, principalmente microcítica hipocrômica, e discretas alterações liquóricas caracterizadas por aumento de proteínas totais $(77,33 \%)$ e pleocitose linfocítica $(50,72 \%)$. A presença de corpúsculos de Lenz em tecidos extraneurais oscilou entre 30 e 45 $\%$, com maior freqüência em linfonodos. Enquanto outras anormalidades clínicas, neurológicas e laboratoriais não tiveram freqüência expressiva para dar apoio ao diagnóstico, o incorreto programa de vacinação foi uma constante.

Palavras-chave: doenças dos cães, cinomose, sistema nervoso, diagnóstico.

\section{SUMMARY}

Eighty-one dogs with clinical signs and histological lesions characteristic of distemper encephalomyelitis were evaluated. Only dogs with Lenz inclusion bodies in the central nervous system were included in the study. High prevalent findings included: changes in postural reactions $(87.65 \%)$, decreased tear production (83.95\%), myoclonus (75.30\%), paresis $(69.12 \%)$, conjunctivitis (56.79\%), chorioretinitis/digital and nasal hyperkeratosis (51.85\%). Anemia (48.05\%), lymphopenia (51.95\%), and mild changes in the cerebrospinal fluid characterized by increase in total protein (77.33\%) and lymphocytic pleocytosis (50.72\%) were common laboratorial findings. Presence of Lenz inclusions bodies in tissues other than nervous system varied from 30 to $45 \%$, with a higher frequence in the limph nodes. Other abnormalities in physical, neurological and laboratorial examinations were not helpful in establishing the diagnosis. Most animals examined were not properly vaccinated.

Key words: diseases of dogs, canine distemper, nervous system, diagnosis.

\section{INTRODUÇÃO}

Cinomose é uma grave doença infecciosa, altamente contagiosa, com elevado índice de mortalidade e geradora de transtornos oculares, respiratórios, gastrintestinais e neurológicos (GREENE, 1984). É uma das doenças neurológicas mais comuns em cães (CHRISMAN, 1991). Segundo WHEELER (1995), é a doença infecciosa do sistema nervoso mais comum nesta espécie. Deve-se suspeitar desta doença quando o cão não for corretamente vacinado (BRAUND, 1994).

${ }^{1}$ Médico Veterinário, Doutor, Professor Adjunto 3, Departamento de Clínicas Veterinárias, Centro de Ciências Agrárias da Universidade Estadual de Londrina (UEL), Caixa Postal 6001, 86051-970, Londrina, PR. Autor para correspondência.

${ }^{2}$ Médico Veterinário, Mestre, Professor Assistente 1, Departamento de Anatomia, Centro de Ciências Biológicas, UEL.

${ }^{3}$ Médico Veterinário, Mestre, Professor Assistente 3, Departamento de Medicina Veterinária Preventiva, Centro de Ciências Agrárias, UEL.

${ }^{4}$ Médico Veterinário, Doutor, Professor Adjunto 1, Faculdade de Medicina Veterinária e Zootecnia, UNESP, Campus de Botucatu, SP.

${ }^{5}$ Médico Veterinário, Mestre, Professor Adjunto 4, Departamento de Medicina Veterinária Peventiva, UEL. 
As lesões e os sinais clínicos da forma neurológica da cinomose são extremamente variáveis (VANDEVELDE \& CACHIN, 1992). São descritas quatro formas de encefalite: uma que afeta os cães novos, de caráter severo e agudo, na qual os sinais sistêmicos ocorrem ao mesmo tempo que os neurológicos; outra que atinge cães adultos, do tipo crônica, na qual os distúrbios neurológicos podem aparecer desacompanhados de transtornos sistêmicos e outras duas denominadas encefalite do cão velho e encefalite recidivante crônica (BRAUND, 1994).

Segundo VANDEVELDE \& CACHIN (1992), $50 \%$ dos pacientes têm sinais sistêmicos antes ou concomitantemente aos neurológicos. É relatado que a encefalomielite ocorre comumentemente em animais com hiperqueratose (WHEELER, 1995) e raramente em filhotes com impetigo (GREENE, 1984; BRAUND, 1994).

Os sinais neurológicos mais comumente observados em cães com cinomose sâo: cegueira, convulsões, ataxias cerebelar, vestibular ou sensorial e mioclonias (GREENE, 1984; VANDEVELDE \& CACHIM, 1992). Estas mioclonias são constatadas mais comumente nos músculos faciais, mastigatórios e apendiculares (BRAUND, 1994) e foram consideradas como sendo patognomônicas da cinomose (FARROW \& LOVE, 1983). JONES \& HUNT (1983) e VANDEVELDE \& CACHIN (1992) mencionaram que ocorrem em $50 \%$ e $33 \%$ dos cães com encefalomielite por cinomose, respectivamente.

Apesar de nenhum sinal clínico ser patognomônico da cinomose, a ocorrência simultânea de um grupo deles facilita o diagnóstico da doença (APPEL \& CARMICHAEL, 1979). Distúrbios neurológicos multifocais acompanhados de febre, transtornos respiratórios, diarréia, corrimento ocular, hiperqueratose naso-digital, mioclonias, linfopenia, coriorretinite e história de não vacinação são indicativos de cinomose (FARROW \& LOVE, 1983; BRAUND, 1994; SUMMERS et al., 1995).

Cães com cinomose apresentam leucopenia 4 a 6 dias após a infecção. Uma vez que a doença esteja instalada, observar-se-á linfopenia, monocitose e leve neutrofilia (APPEL \& CARMICHAEL, 1979; FARROW \& LOVE, 1983; GREENE, 1984), podendo haver leucocitose devido à infecção bacteriana secundária (JAIN, 1993).

Cães com encefalomielite por cinomose podem ou não apresentar alterações no líquor (SHELL, 1990). As anormalidades possíveis de serem encontradas são: aumento de proteínas (superior a $25 \mathrm{mg} / \mathrm{dl}$ ) e pleocitose (mais de 10 células $/ \mathrm{mm}^{3}$ ), com predomínio de mononucleares (GREENE, 1984; CHRISMAN, 1991; BRAUND, 1994).
A cinomose pode ser diagnosticada laboratorialmente através da visualização de corpúsculos de inclusão de Lenz em esfregaços sangüíneos, no líquor e em impressões das mucosas nasal, prepucial, vaginal e principalmente conjuntival (GELATT, 1981; GREENE, 1984; CHRISMAN, 1991). Segundo APPEL \& CARMICHAEL (1979), o encontro destes corpúsculos de inclusão em células das conjuntivas ocular ou vaginal é sinal patognomônico de cinomose. Inclusões intracitoplasmáticas e intranucleares podem também ocorrer em neurônios, astrócitos, células das meninges e epêndima (BRAUND et al.,1987). O diagnóstico da cinomose pode ser sugerido pelo achado destes corpúsculos de inclusão no sistema nervoso (WHEELER, 1995). Na eletroencefalografia de cães com cinomose nervosa são observados traçados típicos de encefalopatia difusa e inflamatória, clássicos dessa doença (REDDING, 1987).

Esta pesquisa tem como objetivo estabelecer o grau de importância dos diferentes sinais clínicos e laboratoriais na cinomose nervosa, esperando conhecer quais destes achados são mais típicos e sugestivos da forma neurológica da doença.

\section{MATERIAIS E MÉTODOS}

Para a realização desta pesquisa foram utilizados 81 cães, com distúrbios sistêmicos e neurológicos sugestivos de infecção pelo vírus da cinomose. Em todos os casos foram realizados anamnese, exames físico e neurológico, exame oftalmológico incluindo fundoscopia e teste I de Schirmer (GELATT, 1981), hemograma, análise de líquor, pesquisa de corpúsculos de Lenz e histologia do sistema nervoso central (SNC). Em 34 destes animais foi também realizada eletroencefalografia.

Para a obtenção do hemograma, contaram-se hemácias e leucócitos na câmara de Newbauer. Para a determinação do volume globular utilizou-se a técnica do microhematócrito, centrifugando as amostras durante 5 minutos a $10.000 \mathrm{rpm}$. A determinação da concentração de hemoglobina foi feita pela técnica da cianometahemoglobina.

Determinou-se a concentração de proteína e glicose liquóricas pelos métodos do ácido tricloroacético e ortotoluidina respectivamente. O aumento de globulinas neste líquido orgânico foi verificado pelas técnicas de Nonne Apelt e Pandy (BENJAMIN, 1978). A citologia do mesmo foi realizada corando-se com Giemsa (BEHMER, 1976) as células concentradas por sedimentação (CHRISMAN, 1991). Os resultados do hemograma e do líquor foram confrontados com os valores de 
normalidade descritos em KIRK (1986). Os traçados eletroencefalográficos foram obtidos se-guindo-se técnica descrita por REDDING (1987) e inibindo-se toda mioclonia e atividade muscular voluntária mediante a administração intravenosa de triiodeto de galamina na dose de $1 \mathrm{mg} / \mathrm{kg}$.

Em 53 dos 81 cães procurou-se corpúsculos de Lenz em células da conjuntiva ocular e das mucosas prepucial ou vaginal, assim como, em impressões feitas a partir de pulmões, do epitélio vesical e linfonodos, todos corados pelas colorações de Shorr (BEHMER, 1976) e de Sellers (BIER,1977). Estas impressões foram realizadas durante a necropsia, na qual também foram coletados fragmentos do encéfalo e/ou da medula espinhal, selecionados pela análise das disfunções neurológicas. O tecido nervoso coletado foi fixado em solução de formol a $10 \%$, desidratado em concentrações crescentes de álcoois, incluído em parafina, cortado e corado pela técnica da hematoxilinaeosina. Só foram incluídos nesta pesquisa cães com corpúsculos de Lenz no SNC.

\section{RESULTADOS}

Verificou-se através da anamnese que 70,37 $\%$ dos pacientes nunca haviam sido vacinados contra cinomose, $11,11 \%$ receberam somente uma dose desta mesma vacina e que apenas $18,52 \%$ dos pacientes forma submetidos a um correto programa de vacinação.

A freqüência dos achados não neurológicos consta na Tabela 1. Diminuição da secreção lacrimal, conjuntivite mucopurulenta, sinais de lesão retinal e hiperqueratose naso-digital foram constatados em mais da metade das unidades experimentais. Impetigo abdominal ocorreu somente em 18,51\% dos cães.

Tabela 1 - Froquercia (f) doe achados ntio nemológicos am

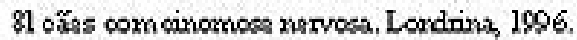

\begin{tabular}{|c|c|c|}
\hline$A_{c}$ hadb & i & $\%$ \\
\hline Schimer $<10$ rrwn & 68 & 83,05 \\
\hline Conjumitivite & 46 & 56,79 \\
\hline Coniorretirite/hiperqueratose nacodigital & 42 & 51,85 \\
\hline Hipertersia $\left(>00,5^{\circ} \mathrm{C}\right)$ & 19 & 23,45 \\
\hline Dianreia & 17 & 20,08 \\
\hline Rinite & 16 & 10,75 \\
\hline Impetigo abdorninal & is & 18,51 \\
\hline Hipotarixia $\left(<8^{\circ} \mathrm{C}\right)$ & 11 & 13,58 \\
\hline Buoncopreuxomia & 10 & 1234 \\
\hline Otite cenurriross & 08 & 09,87 \\
\hline Ulcera de cómea & 03 & 03,70 \\
\hline
\end{tabular}

Observando-se a incidência dos sinais neurológicos apresentados na Tabela 2, foi possível verificar que a perda de reações posturais, a presença de mioclonias e a ocorrência de paresias foram as anormalidades mais freqüentes. Cegueira e paralisia de mandíbula ocorreram em menos de $10 \%$ dos casos.

Tabela 2 - Frequiżncia (f) dos sinais remoló gicos em 81 cães corn oirorose nenosa. Lordina, 1996.

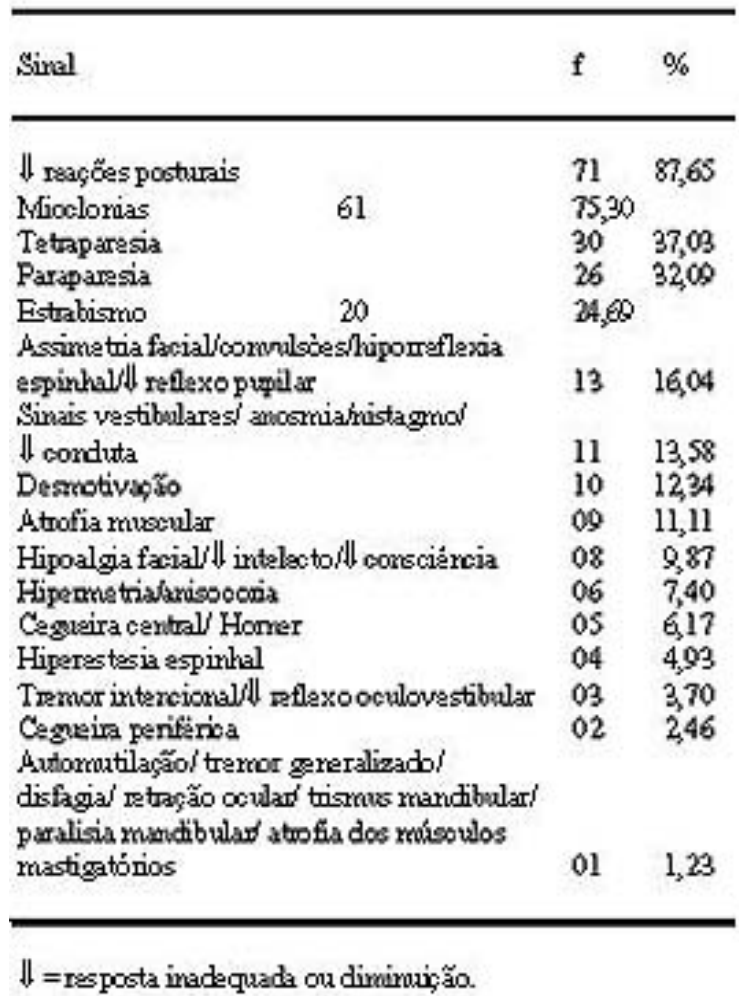

Analisando-se os dados do hemograma, constantes nas Tabelas 3 e 4, pode-se inferir que as alterações hematológicas mais freqüentes foram anemia, leucocitose, neutrofilia e principalmente linfopenia. A anemia foi principalmente dos tipos microcítica $(64,86 \%)$ e hipocrômica $(72,97 \%)$, sendo nas outras vezes dos tipos normocítica $(29,72 \%)$, macrocítica $(5,40 \%)$ e normocrômica $(13,51 \%)$. Alteração do número normal de leucócitos e neutrófilos foi verificada em $48,05 \%$ e $42,84 \%$ dos casos, respectivamente. $\mathrm{O}$ número de linfócitos situou-se dentro da normalidade (1000-4800/mm3 ) em 48,71\% dos casos.

Pelo estudo da Tabela 5, verificou-se que as alterações do líquor apesar de freqüentes eram discretas, caracterizadas pelo aumento de proteínas totais $(77,33 \%)$ e pleocitose com predomínio de

Ciência Rural, v. 27, n. 2, 1997. 


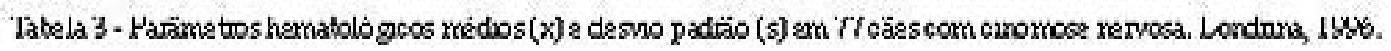



Tabela 4 - Freqüència dos achados hematológicos $\mathrm{em} 77$ calcs con cinomose, Londrina. 1996.

\begin{tabular}{lll}
\hline Parametro & AIE* & $\%$ \\
\hline Anemia $\left(<5,5 \times 10 \% \mathrm{~mm}^{3}\right)$ & & \\
Leucocilose $\left(>17.000 / \mathrm{mm}^{3}\right)$ & $37 / 77$ & 48,05 \\
leucopenia $\left(<6.000 / \mathrm{mm}^{3}\right)$ & $26 / 77$ & 33,77 \\
Neutrofilia $\left(\$ 11.500 / \mathrm{mm}^{3}\right)$ & $11 / 77$ & 14.28 \\
Neutropenia $\left(<3.000 / \mathrm{mm}^{3}\right)$ & $31 / 77$ & 40.25 \\
Linfopenia $\left(<1.000 / \mathrm{mm}^{3}\right)$ & $02 / 77$ & 02,59 \\
& $40 / 77$ & 51.95 \\
\hline
\end{tabular}

- relaça achados/estudados. linfócitos $(50,72 \%)$. Houve ausência de pleocitose e pleocitose mista em $42,03 \%$ e 7,25\% das amostras respectivamente, não sendo constatada pleocitose exclusivamente neutrofílica em nenhum caso. A presença dos corpúsculos de Lenz nos diferentes órgãos, exceto SNC, consta na Tabela 6, e ocorreu mais freqüientemente nos linfonodos.

Com relação ao exame eletroencefalográfico foi constatado que conforme o estado orgânico e região do encéfalo afetada, era possível encontrar traçados com: alta voltagem-baixa freqüência $(23,52 \%)$, voltagem normal-baixa freqüência $(17,54 \%)$, voltagem e freqüencia normais $(35,29 \%)$ e tendência à isoeletricidade $(23,52 \%)$. Este último tipo de traçado foi mais freqüente em cães desidratados, caquéticos e hipotérmicos. Quando os sinais neurológicos não evidenciaram lesões tele- ou diencefálicas e os animais exibiam estado orgânico pouco deteriorado, as eletroencefalografias foram normais.

\begin{tabular}{|c|c|c|c|c|c|}
\hline Paráneıso (valnะ notmal) & Achado & f & $\bar{x}$ & s & $\%$ \\
\hline Cor (incolor) & $\begin{array}{l}\text { hemorrágico } \\
\text { xantocrómico }\end{array}$ & $\frac{2}{3}$ & $\dot{.}$ & $\dot{-}$ & $\begin{array}{l}2.98 \\
4.48\end{array}$ \\
\hline Aspecto (limpido) & $\begin{array}{l}\text { semi-nurvo } \\
\text { turvo }\end{array}$ & $\begin{array}{l}2 \\
4\end{array}$ & $\dot{.}$ & - & $\begin{array}{l}2,98 \\
5,97\end{array}$ \\
\hline $\begin{array}{l}\text { Glicose }(61-116 \mathrm{mg} / \mathrm{dl}) \\
\text { Proteina (c } 25 \mathrm{mg} \text { idi) }\end{array}$ & $\begin{array}{l}10-250 \\
0.400\end{array}$ & $\therefore$ & $\begin{array}{l}61.17 \\
59.61\end{array}$ & $\begin{array}{l}45,25 \\
34,17\end{array}$ &  \\
\hline Nonne apelt (negativo) & positivo & 16 & - & - & 23,88 \\
\hline Pandy (negativo) & positivo & 17 & 50 & - & 25.37 \\
\hline Henicias $\left(0 / \mathrm{mm}^{3}\right)$ & $0 . \$ 07$ & $\cdot$ & 29.48 & 86.06 & - \\
\hline Leucocitos (s 5/mm') & $0-156$ & - & 19.22 & 30.41 & - \\
\hline Segmentados $\left(0 / \mathrm{mm}^{5}\right)$ & $0-100 \%$ & - & 17,83 & 19,37 & - \\
\hline 1.infocitos $\left(5.5 / \mathrm{mm}^{3}\right)$ & $0.100 \%$ & - & 65,91 & 34.17 & - \\
\hline Monocitos $\left(0 / \mathrm{mm}^{\prime}\right)^{\prime}$ & $0-6 \%$ & $\cdot$ & 0,18 & 0,96 & - \\
\hline
\end{tabular}

$f=$ frequência; $\bar{x}=$ média; $s$ - desvio padraso.

\section{DISCUSSÃO CONCLUSÕES}

$\mathbf{E}$

Para APPEL \& CARMICHAEL (1979) e FARROW \& LOVE (1983), apesar de nenhum sinal clínico ser patognomônico da cinomose, a ocorrência simultânea de distúrbios neurológicos multifocais acompanhados de febre, 
Tabela 6 - Identificąäo de corpúsculo de Lenz $\mathrm{cm}$ cales com cinomose nervosil Londrink, 1996 ,

\begin{tabular}{lcc}
\hline Tecido & M/E* & $\%$ \\
\hline Linfonodos & $24 / 53$ & 45,28 \\
Pulmonar & $18 / 49$ & 36,73 \\
Conjuntiva ocular & $19 / 52$ & 36,54 \\
Bexiga & $16 / 52$ & 30,77 \\
Mucosa genital & $15 / 49$ & 30,61 \\
\hline
\end{tabular}

- relaçáo achados/cstudados.

transtornos respiratórios, diarréia, corrimento ocular, hiperqueratose, mioclonias, linfopenia, coriorretinite e história de não vacinação são indicativos de cinomose. Os dados desta pesquisa corroboram parcialmente esta afirmação e colocam como sinais que sugerem a presença de cinomose nervosa o conjunto das seguintes alterações: ceratoconjuntivite seca, conjuntivite mucopurulenta, coriorretinite, hiperqueratose naso-digital, quadro neurológico multifocal, perda de reações posturais, mioclonias, para- ou tetraparesias, linfopenia e líquor com leves aumentos de proteínas e leucócitos mononucleares.

Embora RAW et al. (1992) não tenham suspeitado de cinomose em cães com encefalite que receberam somente uma dose de vacinas quando filhotes, segundo TIPOLD et al. (1992), cães não vacinados regularmente podem perder a imunidade $\mathrm{e}$ se infectar. Os resultados desta pesquisa estão de acordo com a afirmação de MARTIM \& KASWAN (1985) e RUDE (1987), de que não só na cinomose sistêmica, mas também na nervosa a falta de vacinas é fator altamente predisponente para a ocorrência da doença.

PARKER (1978), GREENE (1984), BRAUND et al. (1987) e SHELL (1990) relataram a ocorrência de uma grande variedade de sinais neurológicos na cinomose nervosa. O mesmo foi verificado nesta pesquisa, confirmando o caráter multifocal desta doença. Enquanto VANDEVELDE $\boldsymbol{e} t$ al. (1980) afirmaram que todos os cães com cinomose nervosa por eles examinados apresentavam os reflexos espinhais aumentados, nesta pesquisa, hiporreflexia ocorreu em $16 \%$ dos animais, possivelmente devido a lesões necróticas situadas na medula espinhal, semelhantes às observadas na substância cinzenta cerebral por LISIAK \& VANDEVELDE (1979).
Segundo GREENE (1984), ataxias cerebelar, vestibular ou sensorial e mioclonias são os sinais mais comumente observados na cinomose nervosa. Enquanto para PARKER (1978), mioclonias, convulsões, paresias, depressão da consiência, desorientação e transtornos da conduta são os sinais mais comuns, para SAFARTY et al. (1986) o são as paresias. Nesta pesquisa, a alteração das reações posturais, a presença de mioclonias e para- ou tetraparesias foram os únicos sinais neurológicos vistos em mais da metade dos animais. Apesar das mioclonias também ocorrerem em cães intoxicados pelo chumbo ou sofrendo de encefalomielite por Toxoplasma gondii ou pelo vírus da parainfluenza (DE LAHUNTA, 1983; GREENE, 1984), concorda-se com SHELL (1990) ao afirmar que a cinomose nervosa é a causa mais comum. Além disto, a frequiência de apresentação nesta pesquisa superou as constatadas por JONES \& HUNT (1983) e VANDE-VELDE \& CACHIN (1992), que tinham verificado mioclonias em $50 \%$ e $33 \%$ dos cães com encefalomielite por cinomose, respectivamente, talvez por tratar-se de amostra de vírus diferente (DE LAHUNTA, 1983).

Conforme mencionado por PARKER (1978), verificou-se nesta pesquisa, que sinais como automutilação, paralisias flácidas e masticatórias, distúrbios vestibulares, tremor de intenção, hipermetria, midríase, cegueira, paralisia facial e síndrome de Horner tem baixa freqüência de apresentação nos cães com encefalomielite pelo vírus da cinomose. Por outro lado, confirmaram-se as afirmações de GREENE (1984), BRAUND (1994) e WHEELER (1995), de que a cinomose nervosa é freqüentemente acompanhada de hiperqueratose naso-digital, mas ocorre raramente em cães com impetigo abdominal.

A diferença entre as freqüências de apresentação das cegueiras e de corioretinite, com predomínio desta última, pode ter decorrido de que lesões retinianas não muito severas podem ser acompanhadas de preservação da acuidade visual (GELATT,1981).

Com relação aos parâmetros sangüíneos, a literatura consultada relata na cinomose sistêmica, leucocitose, neutrofilia, neutropenia, linfopenia, monocitopenia, e trombocitopenia (GREENE, 1984; AXTHELM \& KRAKOWKA, 1987; RUDE, 1987; SHELL, 1990 e JAIN, 1993). Para a cinomose nervosa foi mencionado leucopenia (BREAZILE $\boldsymbol{e t}$ al., 1966) e ausência de alterações hematológicas (SHELL, 1990). Já nesta pesquisa, estudando pacientes em fase nervosa, os resultados diferiram, com ocorrência de anemia, principalmente microcítica e hipocrômica, leucocitose, neutrofilia e linfopenia. 
Com relação ao líquor, os achados correspondem aos já citados na literatura (GREENE, 1984; BRAUND, 1994), no que tange à ocorrência de aumento de proteínas e leucócitos mononucleares, em cães com cinomose nervosa. A baixa magnitude destes aumentos quando comparada com alterações maiores, passíveis de ocorrer noutras doenças do SNC, sugerem a cinomose como doença causal. Apesar de que as alterações no neurópilo pareceriam decorrer de mecanismos imunomediados intratecais (VANDEVELDE \& CACHIM, 1992), o aumento de globulinas liquóricas tão só em $25,37 \%$ dos animais desta pesquisa, pareceria confirmar que as lesões também podem ser provocadas pelo vírus, citocinas de astrócitos e/ou radicais livres liberados por macrófagos (SUMMERS et al., 1995).

Enquanto alguns cães apresentaram eletroencefalogramas alterados, clássicos da encefalite provocada pelo vírus da cinomose (REDDING, 1987), outros exibiram exames normais ou isoelétricos. A ausência de alterações ocorre em animais sem lesões no tele- ou diencéfalo (REDDING, 1987). Eletroencefalogramas isoelétricos podem ter decorrido da hipotensão ou hipotermia que alguns cães exibiam (BLACK, 1990).

Conforme indicado por LISIAK \& VANDEVELDE (1979) e SAFARTY et al. (1986) o diagnóstico da cinomose nervosa, nos cães desta pesquisa, foi concluído através do achado de corpúsculos de Lenz no SNC. Caso estivesse baseado no achado dos mesmos, em órgãos outros que o SNC, como fora realizado por GREENE (1984) e CHRISMAN (1991), muitos cães teriam sido excluídos da pesquisa, apesar de sofrerem encefalomielite pelo vírus da cinomose. Entretanto a afirmação de RUDE (1987), de procurar corpúsculos de Lenz em biópsias de linfonodos, tem certa validade, frente aos resultados aqui obtidos.

As principais alterações encontradas em cães com cinomose na fase nervosa foram: alteração das reações posturais, presença de mioclonias, paresias, diminuição da secreção lacrimal, conjuntivite, corioretinite, hiperqueratose naso-digital, linfopenia, anemia e discretas alterações liquóricas caracterizadas por aumento de proteínas totais e pleocitose. Enquanto outras anormalidades clínicas, neurológicas e laboratoriais não tiveram freqüência expressiva para dar apoio ao diagnóstico, o incorreto programa de vacinação foi uma constante.

\section{REFERÊNCIAS BIBLIOGRÁFICAS}

APPEL, M.J., CARMICHAEL, L.E. Systemic viral diseases. In:
CATCOTT, E.J. Canine Medicine. 4. ed. Santa Barbara: American Veterinary Publications, 1979. p. 17-48.

AXTHELM, M.K., KRAKOWKA, S. Canine distemper virus induced thrombocytopenia. American Journal of Veterinary Research, v. 48, n. 8, p. 1269-75, 1987.

BEHMER, O.A., TOLOSA, E.M.C., FREITAS NETO, A.G. Manual de técnicas para histologia normal e patológica. São Paulo: Edart, 1976, 239 p.

BENJAMIN, M.M. Outline of veterinary clinical pathology. 3. ed. Iowa: Iowa State University, 1978. 351 p.

BIER, O. Bacteriologia e imunologia. 18. ed. São Paulo: Melhoramentos, 1977. $1056 \mathrm{p}$.

BLACK, P. Mc. L. Brain death. In: YOUMANS, J.R. Neurological surgery. 3 ed. Philadelphia: Saunders, 1990. V. 1. cap. 20, p. 602-619.

BRAUND, K.G., BREWER, B.D., MAYHEW, I.G. Inflamatory, infectious, immune, parasitic and vascular disease. In: OLIVER, J.E.; HOERLEIN, B.F.,MAYHEW, I.G. Veterinary neurology. Philadelphia: Saunders, 1987. Cap. 7, p. 21644.

BRAUND, K.G. Clinical syndromes in veterinary neurology. 2. ed. St. Louis: Mosby, 1994. 477 p.

BREAZILE, J.E., BLAUGH, B.S., NAIL, N. Experimental study of canine distemper myoclonus. American Journal of Veterinary Research, v. 27, n. 120, p. 1375-1378, 1966.

CHRISMAN, C.L. Problems in small animal neurology. 2. ed. Philadelphia: Lea \& Febiger, 1991. 526 p.

DE LAHUNTA, A. Veterinary neuroanatomy and clinical neurology. 2. ed. Philadelphia: Saunders, 1983, 471 p.

FARROW, B.R.H., LOVE, D.N. Bacterial, viral and other infectious problems. In: ETTINGER, S.J. Textbook of veterinary internal medicine. Diseases of the $\operatorname{dog}$ and cat. 2 . ed. Philadelphia: Saunders, 1983. Cap. 27. p. 269-319.

GELATT, K.N. Textbook of veterinary ophtalmology. Philadelphia: Lea \& Febiger, 1981. 788 p.

GREENE, C.E. Clinical microbiology and infectious disease of the dog and cat. Philadelphia: Saunders, 1984, 967 p.

JAIN, N.C. Essentials of veterinary hematology. Philadelphia: Lea \& Febiger, 1993. 417 p.

JONES, T.C., HUNT, R.D. Veterinary pathology. 5. ed. Philadelphia: Lea \& Febiger, 1983. 1792 p.

KIRK, R.W. Current veterinary therapy IX. Small animal practice. 9. ed. Philadelphia: Saunders, 1986. 1346 p.

LISIAK, J.A., VANDEVELDE, M. Polioencephalomalacia associated with canine distemper virus infection. Veterinary Pathology, v. 16, p. 650-660, 1979.

MARTIN, C.H. L. , KASWAN, R. Distemper associated keratoconjuntivitis sicca. Journal American Animal Hospital Association, v. 21, n. 3, p. 355-359, 1985. 
PARKER, A.J. The many faces of canine distemper. Canine Practice, v. 5, n. 5, p. 25-28, 1978.

RAW, M.E., PEARSON, G.R., BROWN, P.J., BAUMGÄRTNER, W. Canine distemper infection associated with acute nervous signs in dogs. Veterinary Record, v. 130, p. 291-293, 1992.

REDDING, W.R. Electrophysiologic diagnosis. In: OLIVER, J.E., HOERLEIN, B.F., MAYHEW, I.G. Veterinary neurology. Philadelphia: Saunders, 1987. Cap. 5, p. 111184.

RUDE, T.A. Canine distemper virus: infection and prevention. Canine Practice, v. 14, n. 3, p. 16-24, 1987.

SAFARTY, D., CARRILlo, J.M., GREENLEE, P.G. Differential diagnosis of granulomatous meningoencephalomyelitis, distemper and suppurative meningoencephalitis in the dog. Journal American Veterinary Medical Association, v. 188, n. 4, p. 387-392, 1986 .
SHELL, L.G. Canine distemper. Compendium on Continuing Education. Small Animal Practice, v. 12, n. 2, p. 173-179, 1990.

SUMMERS, B. A., CUMMINGS, J.F., DE LAHUNTA, A. Veterinary neuropathology. St. Louis: Mosby, 1995. 527 p.

TIPOLD, A., VANDEVELDE, M., JAGGY, A. Neurological manifestations of canine distemper virus infection. Journal Small Animal Practice, v. 33, p. 466-470, 1992.

VANDEVELDE, M., KRISTENSEN, B., BRAUND, K.G., GREENE, C.E., et al. Chronic canine distemper virus encephalitis in mature dogs. Veterinary Pathology, v. 17, p. 17-29, 1980

VANDEVELDE, M., CACHIN, M. The neurological form of canine distemper. In: KIRK, R.W., BONAGURA, J.D. Current veterinary therapy XI. Small animal practice. Philadelphia: Saunders, 1992. p. 1003-1007.

WHEELER, S..J. Manual of small animal neurology. Gloucestershire: British Small Animal Veterinary Association, 1995.256 p. 